\title{
Produção científica da UFRGS representada na Web of Science (2000-2009) ${ }^{1}$
}

\author{
Sônia Domingues Santos Brambilla
}

\begin{abstract}
Doutora em Comunicação e Informação pelo PPGCOM/ UFRGS. Bibliotecária Pesquisadora Parlamentar da Assembleia Legislativa do Estado do Rio Grande do Sul
\end{abstract}

\section{Ida Regina Chittó Stumpf}

\begin{abstract}
Professora Titular do Departamento de Ciência da Informação e do PPGCOM/UFRGS. Coordenadora do Grupo de Estudos em Comunicação Científica/UFRGS. Doutora em Comunicação pela USP. Pesquisadora do CNPq
\end{abstract}

Este trabalho utiliza indicadores bibliométricos de atividade de impacto e de coautoria, para analisar os artigos publicados por autores da Universidade Federal do Rio Grande do Sul (UFRGS), representados na Web of Science (WOS), no período 2000-2009. A revisão teórica aborda ciência, avaliação e indicadores de produção científica. Os artigos estão classificados pela tabela CAPES/CNPq em nove grandes áreas: Ciências Agrárias (CA), Ciências Biológicas (CB), Ciências Exatas e da Terra (CET), Ciências Humanas (CH), Ciências da Saúde (CS), Ciências Sociais Aplicadas (CSA), Engenharias (E), Letras, Linguística e Artes (LLA) e Multidisciplinar (M). Compõem a amostra 9.250 artigos, desdobrados por áreas, autores, periódicos e artigos citados. A produção da UFRGS na WOS aumentou de 512 artigos em 2000, para 9.250 em 2009, com taxa média de crescimento anual de 12,69\%. A maior parte está registrada em inglês e em periódicos de impacto. Sete artigos foram altamente citados, todos em inglês, colaboração internacional e publicados em periódicos de impacto. CET tem 33,19\% das citações recebidas, seguida por CB e CS. A forte tendência para coautoria comprova que a produção científica da UFRGS, na maioria, é feita em colaboração, com faixa predominante de dois a dez autores por trabalho.

\footnotetext{
Principais resultados da tese defendida em 2011 (doutorado em Comunicação e Informação (PPGCOM/ UFRGS)). Versão preliminar aceita para apresentação no XII Encontro Nacional de Pesquisa em Ciência da Informação, realizado em Brasília, 2011.
} 
Palavras-chave: Bibliometria; Produção Científica; Universidade Federal do Rio Grande do Sul.

\section{Scientific production of UFRGS INDEXED at Web of Science (2000- 2009)}

This study uses bibliometric indicators - measuring activity, impact and co-authorship - to analyze the articles published by authors affiliated to the Universidade Federal do Rio Grande do Sul (UFRGS), indexed at Web of Science (WOS) from 2000 to 2009. The literature review addresses science, evaluation and indicators of scientific production. The articles were classified according to the table of CAPES/CNPq in nine broad areas: Agrarian Sciences (CA), Life Sciences $(C B)$, Exact and Earth Sciences (CET), Humanities ( $\mathrm{CH}$ ), Health Sciences (CS), Applied Social Sciences (CSA), Engineering (E), Languages, Linguistics \& Arts (LLA) and Multidisciplinary (M). The sample was composed of 9,250 articles split into areas, authors, journals and cited articles. UFRGS production at WOS increased from 512 in 2000 to 9,250 in 2009, with an average annual growth rate of $12.69 \%$. Most of the scientific production of UFRGS is published in English and in journals with impact. Seven highly cited articles were found, all written in English, with international collaboration and published in journals with high impact. CET appears with $33.19 \%$ cited articles, followed by $C B$ and $C S$. There is a strong trend towards co-authorship showing that the scientific production of UFRGS is done mostly in co-authorship, from two to 10 authors working in collaboration.

Keywords: Bibliometrics; Scientific Production; Universidade Federal do Rio Grande do Sul.

Recebido em 26.04.2012 Aceito em 02.07.2012

\section{Considerações iniciais}

No âmbito da Comunicação Científica e utilizando fundamentos da Bibliometria, é possível avaliar a dimensão da ciência produzida em uma universidade, as áreas do conhecimento melhor representadas, os recursos empregados, processos e produtos científicos. $O$ uso frequente e atual de indicadores bibliométricos permite obter medidas a partir da 
análise estatística dos resultados científicos, cumprindo a finalidade de mensurar e apontar os impactos dos esforços em C\&T, tornando a pesquisa visível e analisável. Assim, os indicadores são instrumentos que, bem utilizados, dentro dos limites impostos pela técnica quantitativa de avaliação da ciência, podem funcionar como um filtro de controle e qualidade, dando acesso à estrutura e orientando a direção das políticas de gestão institucional.

Nesta abordagem, foram analisados os artigos publicados por autores vinculados à Universidade Federal do Rio Grande do Sul (UFRGS), disponíveis na base de dados Web of Science (WOS) do Institut for Scientific Information (ISI)/Thompson Reuters, no período 2000-2009. A justificativa para a investigação ser sobre a UFRGS, baseia-se na inexistência de um estudo que exponha a representatividade da produção científica da instituição e por ser uma universidade pública, que deve prestar contas da sua produção à sociedade. A utilização da WOS apoia-se no fato da base ser uma das mais usadas nos estudos de citação.

Sendo a universidade um importante espaço de atividade científica, pode-se considerar representativo um estudo descritivo e avaliativo a respeito de algumas facetas da pesquisa realizada na UFRGS, que permita a análise das informações sobre as publicações geradas pelos pesquisadores no desempenho de sua função investigativa, no intuito de refletir sobre a natureza, a dinâmica e a magnitude dessa literatura. Além disso, os trabalhos sobre a produtividade de uma instituição evidenciam elos e proveem o reconhecimento dos autores, auxiliam a apontar comportamentos e tendências evolutivas nas áreas do conhecimento e constituem importantes fontes de informação para a gestão de políticas em C\&T. Pretende-se, com o estudo, dar visibilidade à produção científica da UFRGS, mostrando a importância e o impacto do trabalho acadêmico realizado neste sistema científico. Espera-se, também, que outras universidades façam o mesmo com respeito a sua produção, para que se tenha um panorama atual da produção científica universitária brasileira.

As questões que permearam o estudo, portanto, partem da avaliação da ciência produzida em uma universidade, visando pesquisar: quais as características dessa produção científica e que áreas do conhecimento estão representadas na base de dados, estimadas pelas medidas de atividade? Qual a visibilidade da produção científica de pesquisadores da UFRGS, em termos de artigos publicados em periódicos representados em uma base de dados internacional, estimada pelas medidas de impacto e de coautoria? Com base nestas questões, o objetivo principal do trabalho foi o de avaliar a produção científica da UFRGS, em termos dos artigos publicados em periódicos nacionais e estrangeiros, representados na base de dados Web of Science, utilizando medidas de atividade, de impacto e de coautoria.

A ciência, instalada dentro das universidades, encontrou o locus adequado para seu desenvolvimento. Nesse ambiente, começaram a se formar grupos por especialidades, formando comunidades $e$ subcomunidades, de acordo com as especificidades e os interesses em comum, nos quais os alunos ingressavam para ter acesso à supervisão de 
pesquisa e a estudos avançados (ZIMAN, 1981). Essa estrutura departamental persiste até a atualidade, representando a divisão do conhecimento, que, por consequência, leva a uma especialização dos saberes em partes sempre mais específicas.

Como coube à universidade ser o locus da ciência, ela teve que prover seu corpus científico, elevando o ensino superior a um padrão mais avançado, voltado à formação pós-graduada de pesquisadores. Este modelo, iniciado pela Alemanha, no início do séc. XIX, na Universidade de Von Humboldt, foi adotado pela Universidade John Hopkins, dos Estados Unidos, em 1879, e rapidamente incorporado ao modus americano (STUMPF, 1994). No Brasil, o desenvolvimento da pós-graduação começou a partir dos anos 50, quando as universidades, sobretudo as públicas, qualificaram-se para a pesquisa. Foi criado um sistema de bolsas de estudo, incentivando a formação de professores e pesquisadores no exterior, através da CAPES, destinando os recursos para fomento por meio do CNPq. Atualmente, a pós-graduação é responsável pela maior parte da pesquisa realizada no país, que envolve, em seu sistema, pesquisadores/docentes, estudantes de mestrado e doutorado, bolsistas de iniciação científica (estudantes de graduação) e técnicos. Contudo, como situa Schwartzman (2001), a questão crucial consiste em traçar uma perspectiva para a maturidade e o futuro, pois o universo do conhecimento é diversificado, não há unanimidade e, sim, ilhas de competência, nas quais a ciência se desenvolve durante certo tempo.

A departamentalização das universidades, para Meadows (1999, p. 60), seria um reconhecimento das diferenças entre áreas do conhecimento: "Ao contrário de falar sobre diferenças entre disciplinas, é possível perguntar aos pesquisadores universitários quais são os outros departamentos dos quais eles se sentem mais próximos [...] Os acadêmicos costumam dividir as matérias em rígidas (ciências naturais e tecnologias), flexíveis (humanidades) e as que se situam no meio (ciências sociais)". Como os pesquisadores pensam e agem diferentemente, também se comunicam dessa forma, e uma das maneiras de verificar essa hipótese seria pela análise dos trabalhos que publicam e das referências que contêm a outras publicações, constituindo uma frente de pesquisa, através da rede de citações que traça a distribuição e a proximidade entre os pares.

Por fim, pode-se afirmar que a ciência somente se materializa na produção de documentos, que necessitam de canais formais e informais para divulgação, escolhidos pelos autores por sua adequação ao formato, propósito e público a que se destina. Esses canais têm importância relativa, de acordo com o padrão de cada área. Desse modo, alguns cientistas preferem apresentar seus trabalhos em eventos. Outros participam de grupos de trabalho e discussão, onde ideias são debatidas pelos pares. O principal canal formal de divulgação da ciência, em praticamente todas as áreas, ainda é o periódico científico, por agrupar, em um único meio, artigos de diversos autores. O livro, por outro enfoque, vai perdendo espaço como meio de publicação da pesquisa original, pelo custo de produção e pelos prazos dilatados de edição, que 
tornam a informação desatualizada, embora algumas áreas, como as humanidades, continuem preferindo esse canal (MEADOWS, 1999; STUMPF, 1996).

Diferente deste, outro aspecto leva em conta o nível de atividade cooperativa dos pesquisadores entre disciplinas de qualquer nível (autor, instituição, país), adotando como premissa que muitos autores e grupos compartilhando ideias, podem gerar trabalhos mais qualificados. Meadows (1999) chama a atenção para esse fato, alertando que a necessidade de trabalhar em grupo é maior nas ciências "duras", apontando como causa o custo das pesquisas nas áreas físicas e biológicas, que fica diluído quando repartido por grupos. A coautoria também foi abordada por Vanz (2009), que analisou mais de 40.000 artigos publicados por autores brasileiros e indexados no ISI, para investigar as relações de colaboração científica internacional na comunidade brasileira, revelando as áreas mais produtivas da ciência nacional no SCI: a Química, a Biologia, a Física e a Medicina Clínica e Experimental II.

Outra hipótese seria medida pelo impacto, determinado pelo número de vezes em que um artigo é citado por outro autor. Logo, estaria relacionada com o periódico, pois quanto maior o prestígio da fonte maior é o seu potencial de fazer com que os trabalhos sejam acessados. Pode-se utilizar, para tal, o Fator de Impacto (FI), índice formulado por Garfield e disposto no Journal Citation Reports (JCR) do ISI, que revela os periódicos mais citados por área do conhecimento, das bases de dados de citação Science Citation Index e Social Science Citation Index, calculado como "[...] a razão entre o número de citações feitas no corrente ano a itens publicados nesse periódico nos últimos dois anos, e o número de artigos (itens fonte) publicados nos mesmos dois anos pelo mesmo periódico" (MUGNAINI, STREHL, 2008). Assim, um trabalho publicado em um periódico com alto FI teria maior visibilidade. Segundo os autores, o indicador estaria diretamente associado à aceitação de duas premissas: (a) as publicações relevantes são frequentemente citadas; e (b) o conjunto de publicações indexadas pelo ISI é suficiente para apreender os resultados das pesquisas a serem avaliadas. O FI, dentro dessa perspectiva, tem se estabelecido como parâmetro para avaliar a relevância acadêmica de um pesquisador, grupo ou instituição, mesmo em países que tem pouca representatividade em bases de dados internacionais (STREHL, 2003; PACKER; MENEGHINI, 2006).

Considerando, então, que o impacto é uma característica indispensável aos periódicos como canais de comunicação da ciência, a visibilidade seria uma contrapartida obtida mediante o compartilhamento dos trabalhos com a publicação dos resultados e a admissão pelos pares, gerando o pertencimento a uma comunidade científica (MALTRÁS BARBA, 2003; PACKER; MENEGHINI, 2006). Esse seria o sistema científico, constituindo agregados de agentes organizados - as comunidades - que compartilham objetivos, tem relações ou influências uns sobre os outros, são afetados por regras, restrições e dependem de recursos do mesmo âmbito externo. Quando um artigo é altamente citado, os pesquisadores apropriam-se desse conhecimento e a visibilidade aumenta a 
probabilidade dele ser ainda mais citado. Assim, índices elevados de citação são o resultado da decisão de vários pesquisadores em citar um trabalho em particular, sendo o indicador de visibilidade usualmente operacionalizado pela contagem de citações, para verificar o impacto total da produção dos autores na comunidade. Percebe-se a importância desse indicador, mas cabe ressaltar a complexidade de medir qualidade em qualquer âmbito. Além disso, sabe-se que países periféricos não têm a mesma representação em bases de dados internacionais. Pode-se esperar, portanto, que a representação das revistas brasileiras não atinja os mesmos patamares das publicadas pelos países com números mais significativos.

\section{Procedimentos metodológicos}

Nesta pesquisa, avaliou-se, no detalhe, uma parte da produção científica de uma universidade, pelos artigos representados na base de dados WOS. Embora não seja um estudo exaustivo, pois se sabe que muitos periódicos brasileiros não aparecem na base, pode dar uma dimensão do resultado, uma vez que a WOS tem abrangência e cobertura internacional. Por outro lado, a base tem ampliado, significativamente, o número de periódicos $e$, consequentemente, 0 número de artigos indexados. Outro fator relevante é o aumento do período de cobertura das revistas, podendo-se afirmar, nesse sentido, que a visibilidade da pesquisa brasileira deve aumentar com essa evolução.

Em relação à série temporal, foi selecionado o período 2000-2009, por permitir dotar os resultados de estabilidade e detectar possíveis mudanças na atividade científica. Optou-se pelo agrupamento dos artigos em grandes áreas temáticas do conhecimento, de acordo com a classificação elaborada pelo CNPq e CAPES. Embora esta classificação apresente limitações, continua servindo ao propósito das instituições e agências de fomento brasileiras, apesar das dificuldades que apresentam para conciliar os interesses dos gestores e da comunidade científica (SOUZA, 2006). A tabela CAPES/CNPQ sofre constantes atualizações desde sua concepção, em 1986, tendo natureza hierárquica de quatro níveis, divididas em grande área, área, subárea e especialidade, agregadas pelas categorias principais, que foram adotadas neste estudo: Ciências Exatas e da Terra (CET); Ciências Biológicas (CB); Engenharias (E); Ciências da Saúde (CS); Ciências Agrárias (CA); Ciências Sociais Aplicadas (CSA); Ciências Humanas $(\mathrm{CH})$; e Linguística, Letras e Artes (LLA). Para atender a necessidades específicas, a tabela foi acrescida da grande área "Multidisciplinar" (M), arrolando itens que não estavam representados originalmente e reunindo disciplinas de caráter inter/multidisciplinar. Foi realizada a aproximação entre essa tabela e a indexação utilizada pela WOS, que se baseia na classificação das revistas em subcampos ou disciplinas científicas. Entretanto, como foi identificado por Mueller (2005), "[...] pode ter havido simplificações excessivas, por reunir numa mesma categoria pesquisadores cujos interesses específicos, 
afiliações paradigmáticas e métodos de pesquisa sejam diferentes a ponto de influenciar hábitos de comunicação".

Outra fonte de coleta foi o Sistema de Pesquisas da Pró-Reitoria de Pesquisa da UFRGS, para identificar a procedência dos autores. Em relação às entradas, foi vital a colaboração da equipe de automação de Bibliotecas da UFRGS, que forneceu a listagem da produção intelectual 2000-2009, indexada no Sistema de Bibliotecas (SABi). A coleta final dos dados foi realizada em março de 2010, para possibilitar a inclusão de artigos de 2009 incluídos posteriormente. A partir do campo address da base, foram selecionados artigos com, pelo menos, um autor vinculado à UFRGS, do período 2000-2009, sendo os registros organizados no software MSEXCEL $®$. Com esses dados, foi consultado o JCR, para identificar o FI das publicações. Atribuiu-se a contagem de um artigo a cada autor, conforme a metodologia utilizada em outros estudos bibliométricos (VANZ, 2009; MALTRÁS BARBA, 2003; ZIMBA; MUELLER, 2004). Desta maneira, o total de ocorrências não reflete o total de artigos (9.250), que geraram mais de 49.000 entradas por autor.

A normalização de dados, apesar de consumir tempo, é essencial em estudos bibliométricos, uma vez que não há uniformização nos registros das revistas e, consequentemente, na WOS (VANZ, 2009; IRIBARREN MAESTRO, 2006). Desde a importação da base, em que foram encontrados 41 diferentes termos para identificar a UFRGS, a tarefa de padronização mostrou-se complexa. Vanz e Stumpf (2010, p. 69) citam que "[...] diferentes grafias alteram 0 resultado de rankings de produtividade, estudos de co-ocorrência, como co-autoria entre pesquisadores e instituições, e como co-citação". Para Mugnaini (2006), a tarefa de normalização consiste em "[...] transformar dados bibliográficos em dados bibliométricos", para garantir a homogeneidade e permitir a análise estatística das informações.

A fonte para informação sobre o assunto de cada artigo, adotada pelo ISI, é a classificação dos periódicos em que os artigos foram publicados, que pode permear diversas áreas, sendo possível a indexação em até cinco subáreas. Foi realizada uma aproximação entre os termos que aparecem no campo assunto (Subject Category) da WOS com as grandes áreas da tabela da CAPES/CNPq, respeitando o caráter multidisciplinar das revistas. Portanto, foram considerados todos os assuntos constantes nos registros, tendo sido desdobrados os que puderam ser classificados em mais de uma grande área da tabela. Maiores detalhes desses procedimentos estão na tese que gerou este trabalho (BRAMBILLA, 2011). Classificar os trabalhos em campos apropriados é condição básica para a realização de análises bibliométricas, como apontado por Vanz (2009), que adotou a tabela de Glänzel e Schubert (2003) em estudo sobre colaboração, utilizando a WOS. Para os autores, a categoria Multidisciplinar deveria ser analisada individualmente, como foi aqui realizado, visto que alguns periódicos publicam artigos de diversas áreas.

Para atingir o objetivo principal da pesquisa, três etapas operacionalizam os objetivos específicos: medições de atividade, para 
verificar quantidade de artigos, áreas temáticas, idioma, títulos de periódicos e autores mais produtivos; medições de impacto, para número de citações, citação por área e citação por periódico; e medições de coautoria, para níveis de coautoria e colaboração. Foram utilizadas, para verificar as características dessa produção científica, diferentes técnicas estatísticas, como segue:

Quadro 1 - Indicadores e Análises

\begin{tabular}{|c|c|}
\hline $\begin{array}{l}\text { Indicadores } \\
\text { Ouantitativos }\end{array}$ & Análises Estatísticas \\
\hline $\begin{array}{l}\text { Atividade } \\
\text { Número de artigos / } \\
\text { Periódicos / } \\
\text { Áreas / Autoria / Idioma }\end{array}$ & $\begin{array}{l}\text { Evolução / Frequência e Interdisciplinaridade / } \\
\text { Distribuição / Dispersão } \\
\text { Índice de Atividade }\end{array}$ \\
\hline $\begin{array}{l}\text { Coautoria } \\
\text { Colaboração }\end{array}$ & $\begin{array}{l}\text { Graus de Colaboração / Perfis de Colaboração } \\
\text { Artigos altamente citados }\end{array}$ \\
\hline $\begin{array}{l}\text { Visibilidade } \\
\text { Relação } \\
\text { Colaboração/Citação } \\
\text { Citações recebidas }\end{array}$ & $\begin{array}{l}\text { Citações recebidas X produção / Índice Relativo de } \\
\text { Citação / Índice Relativo de Não Citação } \\
\text { País / Instituição / Área / Periódico }\end{array}$ \\
\hline Impacto & Fator de Impacto (FI) Distribuição por quartis \\
\hline
\end{tabular}

Fonte: IRIBARREN MAESTRO (2006).

O Índice de Atividade (IA) é um indicador de atividade relativa, que compara a produtividade de uma instituição em uma área frente ao conjunto da produção:

$\mathrm{IA}=\quad \mathrm{n}^{\circ}$. documentos da área no ano /

total da produção da instituição no ano $n^{\circ}$. de documentos da área em todo o período analisado

I áreas

total de documentos da instituição em todo o período e em todas as

A metodologia foi a proposta por Iribarren Maestro (2006), para calcular o esforço global de cada área ao longo dos tempos. Com este índice, é possível verificar a temática observada e prever a esperada, para observar a tendência de crescimento ou a área que concentrou esforços no ano. Entretanto, são avaliadas apenas as áreas com produção acima de nove por cento $(9 \%)$, pois campos que não tem a mesma tradição de pesquisa costumam apresentar picos em certos períodos. Isso acontece, principalmente, no âmbito das Ciências Humanas, Sociais Aplicadas, Linguística, Letras e Artes, que não tem a mesma representação na WOS, em relação às demais ciências. Outro indicador, o número de citações, mede o impacto de uma publicação. Nesse estudo, pelas citações recebidas pelos artigos, verificou-se o índice relativo de citação (IRC) e o índice relativo de não citação (IRNC):

IRC $=$ número de citação por documento de cada área número de documentos da UFRGS 
IRNC $=$ percentual de documentos não citados por área percentual de documentos citados da UFRGS

A análise de citações costuma estar relacionada ainda com o FI. Como este trabalho avaliou áreas temáticas, não seria viável, devido à variação dos hábitos de citação das disciplinas, uma simples comparação dos FIs dos periódicos. Por esse motivo, os valores foram contabilizados por área, sem a preocupação com o FI total da UFRGS, para analisar o impacto e a distribuição das publicações em quartis, obtidos ao dividir a lista de periódicos, ordenada do maior ao menor FI de cada temática, em quatro partes iguais. As medições de coautoria verificaram os níveis de autoria única e múltipla nos trabalhos. A colaboração foi medida nos sete artigos mais citados, nos moldes do artigo publicado por Meneghini e Packer (2006), que identificaram os autores brasileiros mais citados, considerando seus trabalhos os núcleos de excelência da ciência brasileira. As limitações relativas ao tratamento de dados dizem respeito às restrições impostas pelo uso de indicadores bibliométricos para medir a ciência produzida em uma instituição. Segundo Rousseau (2001), a comparação entre diferentes grupos de pesquisa pode ter pouco significado, pois os hábitos de publicação variam entre campos. Uma das limitações mais importantes, porém, foi o número de trabalhos da UFRGS representados na WOS, já que uma parte da produção da universidade não está na base ou as áreas não têm igual representação. Foi, então, composta a primeira amostra com 9.250 artigos, para análise de atividade, impacto e coautoria. Após, foi formada a segunda amostra, com 12.257 ocorrências, para dar suporte à análise das áreas, pelo desdobramento dos artigos classificados pela tabela CAPES/CNPq. Foram, também, formadas amostras pelo desdobramento dos autores por artigo (49.613 ocorrências); 2.194 títulos de periódicos; e 6.941 artigos citados.

\section{Resultados principais}

A produção da UFRGS representada na WOS, nestes dez anos, aumentou consideravelmente, já que, em 2000, eram 512 artigos e, no final do período, 9.250. A taxa de crescimento anual foi significativa, com média de 12,69 ao ano, como mostra a Figura 1:

Figura 1 - Representação da Produção da UFRGS na WOS - 2000/2009

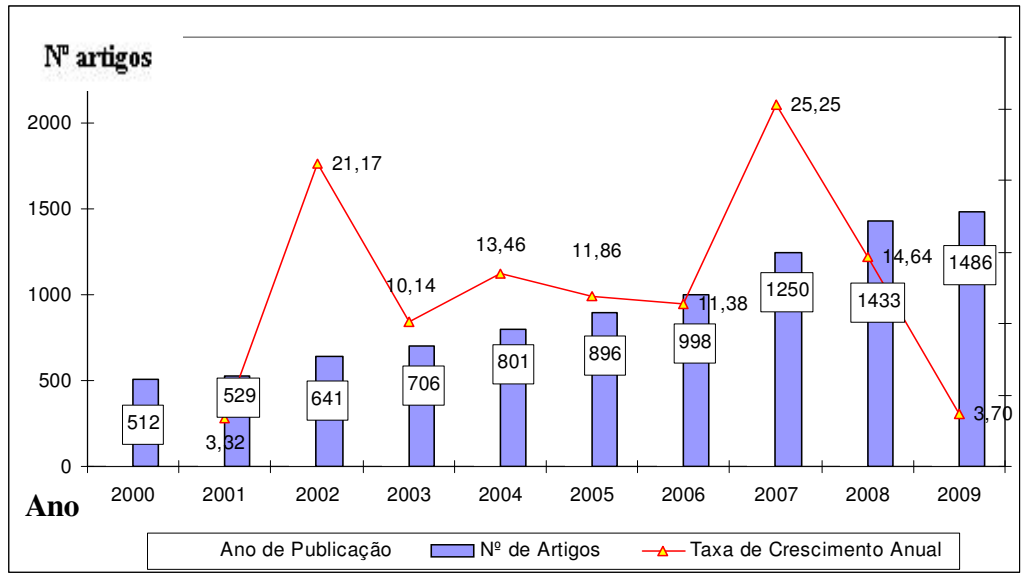


Fonte: Dados da pesquisa.

Nas primeiras análises, utilizando medidas de atividade, foi calculado 0 Índice de Atividade entre as áreas (figura 2). CET apresentaram alto índice no início do período, decaindo ao longo dos anos. CA tiveram o maior crescimento, tendendo fortemente para o aumento de atividade ao longo do período. Engenharias também acompanharam essa tendência, em patamares levemente inferiores. O ano de 2009 não deve ser considerado igual aos outros anos, uma vez que o número de artigos pode ter aumentado após a coleta de dados.

Figura 2 - Índice de Atividade das Áreas do Conhecimento

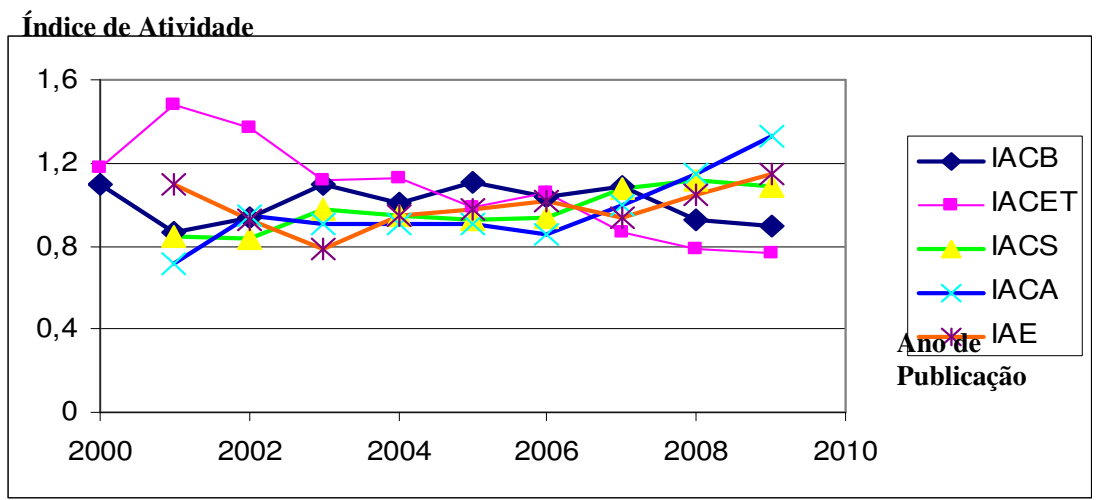

Fonte: Dados da pesquisa.

Em relação à produtividade, as áreas apresentaram os seguintes resultados: CB (28\%), CET (23\%) e CS (23\%) detêm a maior produção em valores absolutos, sendo responsáveis por mais de $74 \%$ do total da UFRGS. CA aparecem na sequência, com 10\%. A somatória dos artigos nas demais áreas é de $16 \%$. O idioma principal foi o inglês, com $90 \%$. Os autores utilizaram 2.097 periódicos estrangeiros (95\%) e 97 nacionais (5\%) para publicação. Foram, em seguida, analisados os 59 títulos de periódicos de preferência dos autores, com pelo menos 30 artigos cada. Foram 16 títulos nacionais e 43 estrangeiros. Dos 3.998 artigos desdobrados por áreas, 1.417 (35\%) estão publicados em periódicos nacionais e 1.164 (29\%) em títulos norte-americanos, compondo mais de $60 \%$ do total da preferência. Os demais estão distribuídos em revistas de seis países europeus, liderados pela Holanda (17\%) e Inglaterra (12\%). 0 FI médio foi 2,510 e apenas dois periódicos, ambos nacionais, não apresentaram impacto: "Ciência Rural", e "Acta Scientiae Veterinariae", das Ciências Agrárias.

Figura 3 - Procedência dos Periódicos da Amostra 


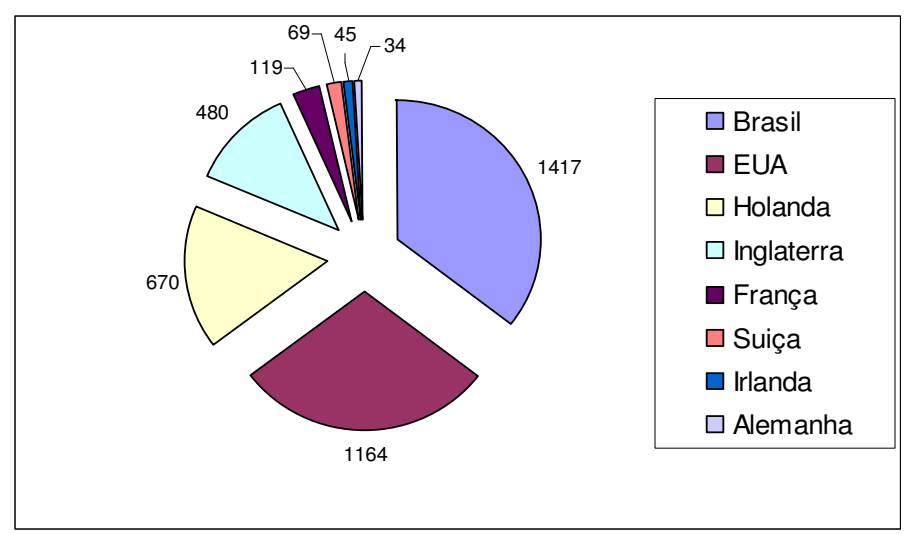

Fonte: Dados da pesquisa.

Para analisar os autores da UFRGS mais produtivos na WOS no período (2000-2009), os 9.250 artigos coletados foram desdobrados por autor, gerando 16.068 entradas autorais e 47.645 registros. A figura 4 apresenta os resultados:

Figura 4 - Número de Artigos por Autor

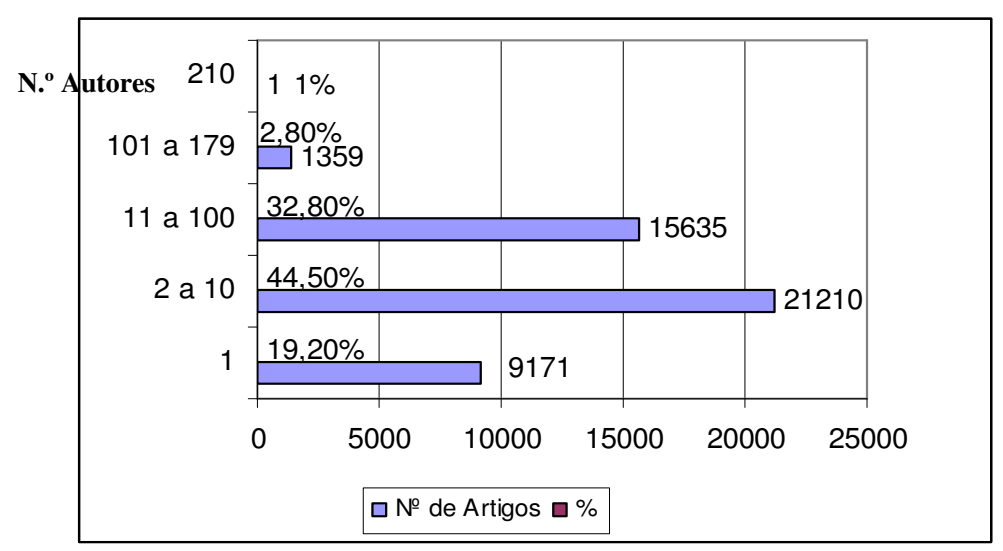

Fonte: Dados da pesquisa.

Observou-se que 9.171 autores $(19,2 \%)$, apareceram com apenas um artigo na WOS. A segunda categoria é a mais representativa, com 21.210 autores $(44,5 \%)$ que publicaram de dois a dez trabalhos, seguida da classe "11 a 100 artigos", com 15.635 autores (32,8\%). Na ordem inversa, 1.359 autores $(2,8 \%)$ publicaram mais de 100 artigos e um pesquisador (menos de $1 \%$ ), tem 210 artigos representados. A média de artigos por autor foi 2,9 (valor central $=1$ ), o que novamente revela alto índice de autores com baixo número de artigos publicados (máximo $=210$ e mínimo = 1). Os autores que apresentaram pelo menos 30 artigos na WOS aparecem com 5.810 trabalhos. Destes, 2.268 são de 40 pesquisadores da área $C B, 1.979$ são de 36 autores nas $C E T, 564$ foram produzidos por 13 autores das CS, 542 artigos por 11 autores das CA, 50 
são de um pesquisador da UFRGS das Engenharias (E) e 407 foram produzidos na área interdisciplinar "CBCS". Os resultados seguem a tendência das demais análises desse estudo, em que as CB e as CET aparecem com a maior representação na WOS. Os dez autores com maior número de artigos estão dispostos no quadro 2, abaixo:

Quadro 2 - Autores mais Produtivos da UFRGS na WOS (2000-2009)

Fonte: Dados da pesquisa.

\begin{tabular}{r|l|c|c}
\hline & \multicolumn{1}{|c|}{ Nome do Autor } & $\begin{array}{c}\mathbf{N}^{\mathbf{0}} \\
\text { Artigos }\end{array}$ & Área \\
\hline 1 & Wajner, Moacir & 210 & CB \\
\hline 2 & Souza, Diogo Onofre Gomes de & 179 & CET \\
\hline 3 & Wyse, Angela Terezinha de Souza & 172 & CET \\
\hline 4 & Wannmacher, Clovis Milton Duval & 123 & CET \\
\hline 5 & Fonseca Moreira, Jose Claudio & 114 & CB \\
\hline 6 & Bica, Eduardo Luiz Damiani & 112 & CET \\
\hline 7 & Dutra Filho, Carlos Severo & 110 & CB \\
\hline 8 & Giugliani, Roberto & 106 & CB CS \\
\hline 9 & Pegas Henriques, Joao Antonio & 102 & CB \\
\hline 10 & Sarkis, Joao Jose de Freitas & 101 & CB \\
\hline
\end{tabular}

Pelas Medidas de Impacto, verificou-se que, dos 9.250 artigos da UFRGS representados na WOS (2000-2009), 6.937 (74,9\%) foram citados. No período da pesquisa, houve 66.738 citações a trabalhos da UFRGS. Os resultados sobre o fator de impacto de 36 periódicos com mais de 100 citações cada, revelou, no $1^{\circ}$. quartil, que agrupou os títulos de maior impacto, 11 títulos. Os $2^{\circ}$. e $3^{\circ}$. quartis apresentaram 10 títulos e o 40. quartil é o menos representativo, com cinco revistas. Entretanto, no 40. quartil, que agrupa os periódicos com menor FI, está o maior número de citações (9.341). Observou-se, também, que as Ciências Exatas e da Terra (CET) apareceram com o maior percentual de citações recebidas $(33,19 \%)$, seguida pelas Ciências Biológicas (CB) e Ciências da Saúde (CS).

Foi também identificado, pelas medidas de coautoria, o principal nível de colaboração, com 2 a 10 autores produzindo um trabalho. Ainda foi possível inferir que, na maior parte $(97,8 \%)$, os artigos são publicados por mais de um autor, sendo a colaboração uma preferência e um padrão na comunicação da ciência na atualidade. Nas duas pontas, autores únicos publicaram 204 artigos $(2,2 \%)$ e 417 autores $(-1 \%)$ colaboraram para a produção de um único trabalho.

Tabela 1 - Níveis de Coautoria nos artigos da UFRGS na WOS (20002009) 


\begin{tabular}{c|c|c}
\hline Número de Autores & $\mathbf{N}^{\mathbf{o}}$. Artigos & \% \\
\hline 1 & 204 & 2,2 \\
\hline 2 a 10 & 8665 & 93,7 \\
\hline 11 a 20 & 317 & 3,4 \\
\hline 21 a 30 & 33 & 0,4 \\
\hline 31 a 50 & 18 & 0,2 \\
\hline 51 a 100 & 9 & 0,1 \\
\hline mais de 100 & 1 & 0,0 \\
\hline Total & 9250 & 100 \\
\hline
\end{tabular}

Fonte: Dados da pesquisa.

O principal nível de coautoria é de 2 a 10 autores, trabalhando em colaboração na produção científica $(93,7 \%)$. É possível inferir que, na maior parte $(97,8 \%)$, os artigos são publicados por mais de um autor, sendo essa uma preferência e um padrão na comunicação dessa comunidade institucional estudada. $O$ artigo com maior número de autores foi classificado na área Multidisciplinar, por ter sido publicado na revista "Nature". No grupo mais forte, de 2 a 10 autores, CB apresentaram o maior grau de colaboração, seguidas por CET e CS. CET aparecem com o maior número de trabalhos escrito em autoria única. As $\mathrm{CH}$ e as CSA, apesar dos hábitos diferenciados em comunicação científica, seguiram a mesma tendência, com maior número de artigos publicados em multiautoria. LLA foram a área de exceção, pois, como indica a literatura, costumam preferir o livro como canal de publicação.

Sete artigos foram altamente citados, com mais de 300 citações cada, sendo três das CET, três das CS e um da área Multidisciplinar. Todos foram escritos no idioma inglês, em coautoria, seis com colaboração internacional e todos publicados em periódicos de alto impacto, tendo, portanto, visibilidade internacional. Em relação à análise sobre colaboração, realizada nestes sete artigos, foi apontado que a produção dos autores vinculados à UFRGS com maior visibilidade acompanha as tendências da pesquisa científica nacional. Sobre isto, cabe inferir que a UFRGS participa de grupos mundiais de pesquisa, que reúnem cientistas e instituições mais conceituadas na atualidade, mesmo que isto tenha sido mostrado por vias indiretas, uma vez que o tamanho da amostra não permite maiores generalizações.

\section{Considerações finais}


Neste estudo, foram abordados os resultados principais da pesquisa, que permitiram avaliar a visibilidade da produção científica de autores vinculados à UFRGS representados na WOS no período 2000-2009. Nestes dez anos, a produção aumentou consideravelmente, de 512 artigos, em 2000 para 9.250 em 2009, sendo as Ciências Agrárias e as Engenharias as áreas com maior índice de atividade. Em valores absolutos, as Ciências Biológicas (28\%), as Ciências Exatas e da Terra (23\%) e as Ciências da Saúde $(23 \%)$ detiveram mais de $70 \%$ do total da produção da UFRGS. 0 idioma principal de publicação dos artigos foi o inglês, com $90 \%$, e os autores utilizaram 2.097 periódicos estrangeiros (95\%) e 97 nacionais (5\%) para registrarem seus trabalhos. Observou-se que 9.171 autores $(19,2 \%)$ aparecem com apenas um artigo na WOS. Na ordem inversa, 1.359 autores (2,8\%) publicaram mais de 100 artigos e um pesquisador tem 210 artigos representados.

Pelas Medidas de Impacto, verificou-se que 74,9\% dos artigos da UFRGS na WOS, já foram citados. As Ciências Exatas e da Terra apareceram com o maior percentual de citações recebidas $(33,19 \%)$, seguida pelas Ciências Biológicas (CB) e Ciências da Saúde (CS). Pelas medidas de coautoria, foi possível inferir que $97,8 \%$ dos artigos foram publicados por mais de um autor, sendo a colaboração uma preferência e um padrão na comunicação da ciência atual e também dessa comunidade institucional. Nas duas pontas, autores únicos publicaram 204 artigos $(2,2 \%)$ e 417 autores (menos de 1\%) colaboraram para a produção de um único trabalho. Sete artigos foram altamente citados, com mais de 300 citações cada, sendo três das Ciências Exatas e da Terra, três das Ciências da Saúde e um da área Multidisciplinar. Todos foram escritos no idioma inglês, em coautoria, seis com colaboração internacional e todos publicados em periódicos de alto impacto.

Pode-se concluir, portanto, que os artigos da UFRGS são, na maioria, feitos em coautoria, registrados em inglês e em periódicos nacionais e estrangeiros de impacto, sendo esta a produção com maior visibilidade. Além disso, as áreas do conhecimento têm influência sobre o número de citações que os artigos recebem de outros autores. Cabe à Universidade, portanto, incentivar, cada vez mais, a colaboração e a troca de experiências entre os seus pesquisadores e os de outras instituições e países, em todos os campos, apesar dos padrões diferenciados de produção e de comunicação da ciência, que refletem maneiras diferentes de fazer pesquisa.

A análise dos dados revelou padrões e comportamentos da ciência produzida na UFRGS e tornou possível a visualização dos núcleos preferenciais de cada área, verificados pelas Medidas de Atividade, Impacto e Coautoria. A pesquisa mostrou-se complexa, pois a UFRGS é uma universidade que abrange todas as áreas do conhecimento e, além disso, apresenta alto índice de interdisciplinaridade entre elas. Diversos enfoques ainda devem ser explorados, para que se conheçam outras 
facetas desta produção científica, abrindo fronteiras que devem ser debatidas continuamente.

Uma das principais recomendações diz respeito ao escopo do trabalho. Poucos estudos já foram realizados sobre a produção científica de universidades brasileiras. Seria importante, utilizando medidas de atividade, impacto e coautoria, testar novamente a metodologia desta pesquisa, destacando a importância dos estudos bibliométricos para que se conheça mais do que mostram os resultados dos rankings nacionais e internacionais.

A UFRGS é referência regional e nacional no ensino superior, como atestam diversas avaliações realizadas, externas e internas, aparecendo nos primeiros lugares entre as instituições de ensino superior do país. 0 interesse por esses resultados reside não só na descrição exaustiva de um conjunto de indicadores, mas, acima de tudo, por permitir a análise da visibilidade alcançada por essa produção. Ainda, pode ter valor para os gestores e para os próprios pesquisadores, por se tratar de uma avaliação objetiva e de uma visão global da atividade investigativa realizada no âmbito da universidade. As instituições precisam conhecer o comportamento diferenciado de produção científica de cada área do conhecimento, para adotar políticas que tornem mais visíveis e utilizáveis essa produção.

\section{Referências}

BRAMBILLA, S. D. S. Produção científica da Universidade Federal do Rio Grande do Sul representada na Web of Science: 2000-2009. 2011. Tese (Doutorado em Comunicação e Informação) - Universidade Federal do Rio Grande do Sul. Faculdade de Biblioteconomia e Comunicação, Porto Alegre, 2001. Disponível em: <http://hdl.handle.net/10183/28922>. Acesso em: 21 jun. 2011.

GLÄNZEL, W.; SCHUBERT, A. A new classification scheme of science fields and subfields designed for scientometric evaluation purposes. Scientometrics, Amsterdan, v. 56, n. 3, p. 357-67, 2003.

IRIBARREN MAESTRO, I. Producción científica y visibilidad de los investigadores de la Universidad Carlos III de Madrid en las Bases de Datos del ISI, 1997-2003. Tese. Universidad Carlos III, Departamento de Biblioteconomia y Documentación. Getafe, Julio de 2006.

MALTRÁS BARBA, B. Los indicadores bibliométricos: fundamentos y aplicación al Análisis de la Ciência. Gijón: Trea, 2003. 
MEADOWS, A. J. A comunicação científica. Brasilia: Briquet de Lemos/Livros, 1999.

MENEGHINI, R; PACKER, A. Articles with authors affiliated to brazilian institutions published from 1994 to 2003 with 100 or more citations: II identification of thematic nuclei of excellence in Brazilian science. Anais da Academia Brasileira de Ciências, v. 78, n. 4, p. 855-883, 2006.

MUELLER, S. P. M. A publicação da ciência: áreas científicas e seus canais preferenciais. DataGramaZero: Revista de Ciência da Informação, v. 6, n.1, fev. 2005. Disponível em: <http://inseer.ibict.br/ancib/index.php/tpbci/article/view/11/9>. Acesso em: 1 jan. 2011.

MUGNAINI, R. Caminhos para adequação da avaliação da produção científica

brasileira: impacto nacional versus internacional. 2006. Tese (Doutorado) - Escola de Comunicações e Artes, Universidade de São Paulo. 2006. Disponível em:

<http://poseca.incubadora.fapesp.br/portal/bdtd/2006/2006-domugnaini_rogerio.pdf.> Acesso em: 10 set. 2009.

MUGNAINI, R.; STREHL, L. Recuperação e impacto da produção científica na era Google: uma análise comparativa entre o Google Acadêmico e a Web of Science. Encontros Bibli, Florianópolis, n. esp., $1^{0}$ sem. 2008.

PACKER, A. L.; MENEGHINI, R. Visibilidade da produção científica. In: POBLACION, D. A.; WITTER, G. P.; SILVA, J. F. M. da. (Orgs.). Comunicação e produção científica: contexto, indicadores, avaliação. São Paulo: Angellara, 2006.

ROUSSEAU, R. Indicadores bibliométricos y econométricos en la evaluación de instituciones científicas. Scientometrics, Amsterdan, v. 51, n. 1, p. 267-92, 2001.

SCHWARTZMAN, S. Um espaço para a ciência: a formação da comunidade científica no Brasil. Brasília: Ministério da Ciência e Tecnologia: 2001.

SOUZA, R. F. de. Organização e representação de áreas do conhecimento em ciência e tecnologia: princípios de agregação em grandes áreas 
segundo diferentes contextos de produção e uso de informação. Encontros Bibli, Florianópolis, n. esp., $1^{0}$ sem. 2006.

STREHL, L. Relação entre algumas características de periódicos de física e seus fatores de impacto. 2003. Dissertação (Mestrado) - Universidade Federal do Rio Grande do Sul, Faculdade de Biblioteconomia e Comunicação, Programa de Pós-Graduação em Comunicação e Informação, Porto Alegre, 2003.

STUMPF. I. R. C. Revistas universitárias: projetos inacabados. 1994. Tese (Doutorado) - Universidade de São Paulo, Escola de Comunicações e Artes, Curso de Pós-Graduação em Ciências da Comunicação, São Paulo, SP, 1994.

STUMPF. I. R. C. Passado e Futuro das Revistas Científicas. Ciência da Informação, Brasília, v. 25, n. 3, p. 383-386, 1996.

VANZ, S. A. de S. As redes atuais de colaboração científica no Brasil. Tese (Doutorado) - Universidade Federal do Rio Grande do Sul. Faculdade de Biblioteconomia e Comunicação, Programa de Pós-Graduação em Comunicação e Informação, Porto Alegre, 2009.

VANZ, S. A. de S.; STUMPF, I. R. C. Procedimentos e ferramentas aplicados aos estudos bibliométricos. Informação \& Sociedade: Estudos, João Pessoa, v. 20, n. 2, p. 67-75, maio/ago. 2010.

ZIMAN, J. A força do conhecimento. Belo Horizonte: Itatiaia, 1981.

ZIMBA, H. F ; MUELLER, S. P. M. Visibilidade científica internacional: o caso da pesquisa na área de medicina veterinária em Moçambique. Informação \& Sociedade: Estudos, João Pessoa, v. 14, n. 1, 2004. 